\title{
The Effect Study of Free Policy on Secondary Vocational Education Quality Improvement in Poor Areas
}

\author{
Yurong $\mathrm{Zhu}^{1}$, Limei $\mathrm{Cao}^{2}$, Jinxiu Yang ${ }^{3}$ \\ ${ }^{1}$ College of Tourism, Sichuan Agricultural University, Dujiangyan, China 611830 \\ ${ }^{2}$ College of Tourism, Hainan University, Haikou ,China 570228 \\ ${ }^{3}$ College of Economics, Sichuan Agricultural University, Chengdu,China 611130 \\ 360517868@qq.com
}

Keywords: Free Policy for Secondary Vocational Education; Education Quality; PSM; Poor Areas of Sichuan Province

\begin{abstract}
Since the free policy for secondary vocational education began, the scope of funding gradually gets enlarged and government financial investment is increasing continuously. The importance of implementation effect evaluation on the free policy for secondary vocational education becomes increasingly prominent, which has aroused widespread concern of the society. Using the survey data in poor areas of Sichuan Province and drawing on the experience of universal education quality framework of UNESCO that takes learners as the core, this paper constructs the evaluation index system of secondary vocational education quality, takes "counterfactual inference model" as the theoretical basis and uses PSM method to make a quantitative assessment with the improvement effect of free policy on secondary vocational education quality. The research results show that the free policy for secondary vocational education has a positive effect on information resources, occupational guidance and education output of secondary vocational education, but does not have significantly positive influence on the curriculum teaching quality and student ability development of secondary vocational education, exposing the problem that targeted objects of the free policy for secondary vocational education is imprecise.
\end{abstract}

\section{Introduction}

As an essential part of vocational education, the secondary vocational education has been transformed into basic public service in policy orientation, and has become a national development concept and strategic choice. As the derivative of its public welfare, the free policy for secondary vocational education began in 2009 and went through a series of reform such as scope extension and policy scope improvement. At present, "Opinion on Perfecting Government Grant-in-aid Policy with Scope Expansion of the Free Tuition Policy for Secondary Vocational Education” jointly issued by the Ministry of Finance and other ministries expands the scope of free tuition policy to all rural (including county and town) students, all urban students who study agriculture-related Specialty or are from poor families (except art performing Specialty) among secondary vocational schools full-time students in grade one or two and three with official status. From 2009 to 2012, central financial institutions arranged assistance funds amounting to be 19 billion 530 million Yuan for tuition free subsidy, and $90 \%$ of secondary vocational school students enjoyed the tuition free policy.

With the subsidizing scope of China's free policy for secondary vocational education expanding and increasing government financial investment, The importance of implementation effect evaluation on the free policy for secondary vocational education becomes increasingly prominent, which has aroused widespread concern of the society. On the one hand, some scholars believe that the free policy for secondary vocational education plays an important role in promoting the education, economy and social harmonious development ${ }^{[7.8]}$; on the other hand, some education 
experts put forward that the implementation effect of this free policy is not optimistic and slow down the full implementation of the free policy for secondary vocational education. This is mainly because the researchers find that the stimulation of the free policy for secondary vocational education is only a short-term effect ${ }^{[9]}$ and deviates from the expected goal of "support agriculture" and "poverty relief", failing to fully achieve fair effect ${ }^{[10]}$ and also failing to achieve good policy objective in benefit standards, efficiency standards, fair standards and policy responses etc. ${ }^{[1]}$. At the same time, the implementation effect of the policy is different in different areas, and the peasant household in backward areas are more responsive to the free policy than those in the developed areas $^{[12]}$. It can be seen that the attention of the scholars on the implementation effect of the free policy for secondary vocational education is gradually warming up with rich academic achievements, but few people study on the implementation effect of free policy for secondary vocational education in poor areas, therefore, researches on improvement effect of the free policy for secondary vocational education quality are more rare.

Using the survey data in poor areas of Sichuan Province and constructing the evaluation index system of secondary vocational education quality, based on the theoretical basis of "counterfactual inference model”, this paper make comprehensive use of PSM method and factor analysis etc. to make a quantitative assessment with the improvement effect of free policy on secondary vocational education quality, extracting the existing deficiency in the process of policy implementation in order to allocate resources.

\section{Data Sources}

Data in this paper comes from the sample survey on 7 secondary vocational schools students in Sichuan province national-level poverty-stricken county and contiguous destitute areas by the "Implementation Effect Research on Free Policy for Secondary Vocational Education in Poor Areas of Sichuan Province" research group of the National Education Science "Twelve-Five Planning" project from Dec. 2014 to Jan. 2015. The questionnaire adopts on-site answering and on-site recycling methods. A total of 1980 questionnaires were issued, collecting 1975 questionnaires, 99.75\% collecting rate, excluding 68 invalid questionnaires, and 1907 valid questionnaires were determined with $96.31 \%$ questionnaire rate.

\subsection{Samples Descriptive Statistics Analysis}

This paper gets 1906 valid samples of the secondary vocational school students. Among the students surveyed, first-year students accounting for $41.5 \%$, second-year students accounting for $32.6 \%$, the third-year students accounting for $25.95 \%$, and the female students accounting for $63.3 \%$ are more than male students; the rural household registration students are in the Specialtyity, accounting for $90.4 \%$; students who study agriculture-related Specialty account for $30.45 \%$ of the students surveyed .

\section{Construction of Secondary Vocational Education Quality Evaluation Index System}

In recent years, domestic and overseas secondary vocational education field accumulated many valuable results in the digital resources system construction and promoting strategy ${ }^{[30]}$, system construction of secondary and higher vocational education harmonious development strategy ${ }^{[31]}$, research on formulation, fairness, performance and subsidizing assessment of the national policy and regulations and local practice, study on relationship between urbanization development and secondary vocational education $^{[35.36]}$, quality evaluation ${ }^{[37][38][39][40]}$ and assurance ${ }^{[41.42]}$ of secondary vocational education, reform of school-running model ${ }^{[43]}$, talent training model ${ }^{[44]}$, course teaching $^{[45]}$, teachers ${ }^{[46]}$ and international comparison ${ }^{[47,48]}$ of secondary vocational education etc.. Study on the secondary vocational education quality evaluation of the domestic scholars is still in the initial stage, taking review and foreign experience quotation as the principal thing, such as Sun 
Ying et al (2014) ${ }^{[30]}$, Ji Xiaoyan (2007) ${ }^{[31]}$, Wu Xueping, Liu Jinhua(2013 $)^{[32]}$, Sun Cuixiang (2014) [33] studying the referential significance of secondary vocational education quality evaluation experience in Japan, Singapore, Russia, the United States, Britain and other countries on China's vocational education.; Drawing on relevant content of universal education quality framework of UNESCO that takes learners as the core, this paper initially determines the evaluation index system of secondary vocational education quality and uses project analysis and factor analysis to confirm the final evaluation index system. After collecting the questionnaires, the project group first uses EXCEL software to establish a database; secondly, after artificially eliminating unreasonable items, make use of SPSS19.0 software to make a project analysis for valid questionnaires, namely calculating the critical ration for each item (CR value), and the results showed that CR value achieves significant level that can identify the reaction degree of different subjects; thirdly, make KMO and Barlett Test of Sphericity to measure its correlation and independence, and the results showed that KMO value of education quality fairness effect questionnaire is 0.927 and significance probability of Barlett Test of Sphericity probability is 0.000 , which indicates that all variables are relevant and are suitable for factor analysis (Table 2): fourthly, use the factor analysis to seek structural validity, orthogonal rotation according to principal component analysis with varimax rotation, selecting the factor with the principle of characteristic value greater than 1,20 indexes coming down to 5 factors which respectively named course teaching, information resources, vocational guidance, educational output and capacity development so as to determine the evaluation index system of vocational education quality in poor areas of Sichuan province (Table 2); fifthly, a reliability test using alpha coefficient, alpha coefficient is 0.899 , showing good reliability (Table 21; sixthly, calculating the score of each factor according to the factor coefficient matrix, the corresponding rotated variance contribution rate of each factor is weight calculation synthesis score (Table 3). The calculation formula of the synthesis score as follows:

$\mathrm{F}=0.23642 \times \mathrm{F} 1+0.14321 \times \mathrm{F} 2+0.11791 \times \mathrm{F} 3+0.08219 \times \mathrm{F} 4+0.07179 \times \mathrm{F} 5$

Table $1 \mathrm{KMO}$ and Bartlett Test and Reliability Test

\begin{tabular}{|c|c|c|c|c|c|c|}
\hline \multirow[t]{2}{*}{$\overline{\text { Scale }}$} & \multicolumn{4}{|c|}{ Sampling sufficient Kaiser Bartlett sphericity test } & \multirow{2}{*}{$\begin{array}{l}\text { Cronbach's } \\
\text { Alpha }\end{array}$} & \multirow[t]{2}{*}{ Items } \\
\hline & $\begin{array}{l}\text {-Meyer-Olkin } \\
\text { measurement }\end{array}$ & $\begin{array}{l}\text { Approximate } \\
\text { chi-square }\end{array}$ & $\mathrm{df}$ & Sig. & & \\
\hline $\begin{array}{l}\text { Education } \\
\text { quality }\end{array}$ & 0.927 & 16024.489 & 190 & 0.000 & 0.899 & 20 \\
\hline
\end{tabular}


Table 2 Secondary Vocational Education Quality Assessment Index System in Poor Areas of Sichuan Province

\begin{tabular}{|c|c|}
\hline First grade index & Second grade index \\
\hline Course teaching & The degree to which professional teaching content meets expectations \\
\hline \multirow[t]{2}{*}{ Information resources } & $\begin{array}{l}\text { The integration degree between the learning course in school and the actual work } \\
\text { Multimedia assisted instruction }\end{array}$ \\
\hline & $\begin{array}{l}\text { The degree to which teaching instruments and equipment can meet my learning } \\
\text { needs } \\
\text { The degree to which school libraries meet learning needs } \\
\text { The degree to which school web services meet learning needs }\end{array}$ \\
\hline Vocational guidance & $\begin{array}{l}\text { The benefit degree that the school organizes professional related activities } \\
\text { The school has channels for students to understand the employment requirements } \\
\text { of employers } \\
\text { The condition that the school offers career guidance } \\
\text { The condition that school guidance helps students plan their future career } \\
\text { development } \\
\text { The condition that the school offers vocational qualification training }\end{array}$ \\
\hline Educational output & Mastery degree of professional knowledge \\
\hline \multirow[t]{5}{*}{ Capacity development } & $\begin{array}{l}\text { Mastery degree of professional skills } \\
\text { Development degree of language competence } \\
\text { Development degree of communicative competence } \\
\text { Development degree of team cooperation ability }\end{array}$ \\
\hline & Development degree of self promotion ability \\
\hline & Development degree of psychological endurance \\
\hline & Development degree of organizational coordination ability \\
\hline & Development degree of innovation ability \\
\hline
\end{tabular}

Table 3 Factor Variance Contribution Rate after Orthogonal Rotation

\begin{tabular}{lllll}
\hline & & \multicolumn{3}{l}{ Rotation square and load } \\
\cline { 3 - 5 } Element & Element name & In total & $10 \%$ of variance & Accumulation \% \\
\hline $\mathrm{F}_{1}$ & Course teaching & 4.728 & 23.642 & 23.642 \\
$\mathrm{~F}_{2}$ & Information resources & 2.864 & 14.321 & 37.963 \\
$\mathrm{~F}_{3}$ & Vocational guidance & 2.358 & 11.791 & 49.754 \\
$\mathrm{~F}_{4}$ & Educational output & 1.644 & 8.219 & 57.973 \\
$\mathrm{~F}_{5}$ & Capacity development & 1.436 & 7.179 & 65.152 \\
\hline
\end{tabular}

\section{Improvement Effect Assessment of Free Policy on Secondary Vocational Education Quality}

The PSM method is an important method of empirical research on the relationship between modern cause and effect with "counterfactual inference model" as the theoretical framework. "Counterfactual inference" assumes that any research object of causal analysis has conditions in two different conditions: the observed result and the potential result that was not observed. From such a "counterfactual" method, any researched object has two results: the object in the experimental group has the result after the experiment (observed) and the result without accepting the experiment (unobserved); similarly, the object in the control group has the result after the experiment (observed) and the result without accepting the experiment (unobserved). Under the guidance of such a theoretical framework, the whole causal analysis has become a step towards making the difference between the two results ${ }^{[31]}$. This is a quasi experimental method to be used for evaluating the intervention effect and can eliminate the deviation caused by confounding factors with good application prospect in the field of education and sociology. The process that this paper 
uses STATA software to estimate is as follows: firstly, build Probit model to get the propensity score; secondly, taking kernel matching to makes sample matching comparison, estimating the value of ATT, ATU, ATE and conducting a balance experiment for matching between the treatment group and control group.

\subsection{Probit Model Evaluation of PSM}

In the STATA12.0 programming environment, use the PSM method to evaluate the net effect of education quality improvement in poor areas of Sichuan province after the implementation of the free policy for secondary vocational education. Using the Probit model in which whether to accept the free policy for secondary vocational education as independent variables with comprehensive factors and the five common factors namely the curriculum teaching, information resources, vocational guidance, educational output, capability development as dependent variables, introducing gender, school key level, household, household enjoying the minimum living guarantee, Specialty, geographical position and GDP and the observable covariates namely individual, family and regional features to estimate the propensity score.

\subsection{Quality Matching Test Results}

Based on the reliability of balance test (Table 4) sample matching for the treatment group and control group before and after matching, the results show that the deviation of GDP between the treatment group and control group was expanding and the deviation of other variables after matching reduced. Overall, Pseudo R2 after matching is less than before matching, which is in accord with the balance test. It shows that the matching process can well balance features of the control group and treatment group, and after matching, the distribution of secondary vocational school students who received the free policy for secondary vocational education and those that did not receive the free policy has no systematic difference or little difference.

Table 4 Matching Variable Balance Test Results

\begin{tabular}{|c|c|c|c|c|c|}
\hline \multirow[t]{2}{*}{ Variable } & \multirow[t]{2}{*}{ Category } & \multicolumn{2}{|c|}{ Mean value } & \multirow{2}{*}{$\begin{array}{l}\text { Deviation } \\
\text { (\%) }\end{array}$} & \multirow{2}{*}{ 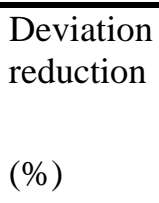 } \\
\hline & & Treatment group & Control group & & \\
\hline Gender & Before matching & 1.628 & 1.377 & 44.700 & \\
\hline School key level & $\begin{array}{l}\text { After matching } \\
\text { Before matching }\end{array}$ & $\begin{array}{l}1.434 \\
1.840\end{array}$ & $\begin{array}{l}1.377 \\
1.208\end{array}$ & $\begin{array}{l}10.100 \\
96.100\end{array}$ & 77.400 \\
\hline & After matching & 1.189 & 1.208 & -2.900 & 97.000 \\
\hline Household & $\begin{array}{l}\text { Before matching } \\
\text { After matching }\end{array}$ & $\begin{array}{l}2.858 \\
2.208\end{array}$ & $\begin{array}{l}2.491 \\
2.491\end{array}$ & $\begin{array}{l}55.000 \\
-42.400\end{array}$ & 22.900 \\
\hline $\begin{array}{l}\text { Household enjoying the } \\
\text { minimum living } \\
\text { guarantee }\end{array}$ & Before matching & 1.783 & 1.359 & 62.900 & \\
\hline Specialty & $\begin{array}{l}\text { After matching } \\
\text { Before matching }\end{array}$ & $\begin{array}{l}1.491 \\
1.695\end{array}$ & $\begin{array}{l}1.359 \\
1.415\end{array}$ & $\begin{array}{l}19.600 \\
41.200\end{array}$ & 68.900 \\
\hline Geographical position & $\begin{array}{l}\text { After matching } \\
\text { Before matching }\end{array}$ & $\begin{array}{l}1.830 \\
2.493\end{array}$ & $\begin{array}{l}1.415 \\
2.981\end{array}$ & $\begin{array}{l}61.100 \\
-92.900\end{array}$ & -48.500 \\
\hline GDP & $\begin{array}{l}\text { After matching } \\
\text { Before matching }\end{array}$ & $\begin{array}{l}2.925 \\
2.084\end{array}$ & $\begin{array}{l}2.981 \\
2.019\end{array}$ & $\begin{array}{l}-10.800 \\
14.900\end{array}$ & 88.400 \\
\hline Pseudo $\mathrm{R}^{2}$ & $\begin{array}{l}\text { After matching } \\
\text { Before matching } \\
\text { After matching }\end{array}$ & $\begin{array}{l}2.084 \\
0.183 \\
0.134\end{array}$ & 2.314 & -53.100 & -256.800 \\
\hline
\end{tabular}




\subsection{Education Quality Improvement Effect Assessment}

The education improvement effect of free policy for secondary vocational education can be reflected by the estimation of Average Treatment Effect on the Treated (ATT) in the treatment group, Average Treatment Effect on the Untreated (ATU) and the Average Treatment Effect (ATE) in the non treatment group. ATT refers to the student group who accept free policy for secondary vocational education, potentially perceiving the average difference of education quality under conditions of accepting policy and not acceptable assumption. ATU refers to the student group who have not accepted the free policy for secondary vocational education, assuming the education quality that may be improved after receiving the policy. "ATE" refers to the average difference of the overall random extraction from any individual accepting the policy and the assumption that the policy is not accepted.

The evaluation index system of secondary vocational education quality includes five dimensions from course teaching, information resources, vocational guidance, educational output and capacity development. PSM estimated results (Table 5) show that ATT of information resources, vocational guidance and educational output can meet the 10\% significant level, while ATT of comprehensive factor, course teaching and capacity development is not significant, which indicates that free policy for secondary vocational education has a significant influence on the overall quality, course teaching and capacity development of secondary vocational education. Further analysis found that from the performance of the average treatment effect, ATT difference for information resources and educational output is negative, which indicates that the implementation of the free policy for secondary vocational education has certain negative effects on information resources and educational output of secondary vocational schools; secondly, ATU difference in the non treatment group of vocational guidance is negative, which indicates that assuming the group who did not accept the policy accept the free policy, promoting degree in vocational guidance dimension may be negatively correlated with the policy; thirdly, ATT difference of vocational guidance dimension is positive, which indicates that the implementation of free policy promoted the development of vocational guidance for secondary vocational schools. Specifically, on one hand, PSM estimation results of comprehensive factor, course teaching, information resources and capacity development show that $0>$ ATT $<$ ATE $<$ ATU, indicating that the positive effect of the group who accept free policy for secondary vocational education on the equity of educational quality, course teaching, information resources and ability innovation is not only lower than the overall randomly selected group, but below the group who do not accepting the policy (assuming the acceptance), having a certain negative. This exposed the problem that targeted objects of the free policy for secondary vocational education is imprecise, that is, the people who can make the policy play a greater utility do not have access to funding policy; on the other hand, PSM estimation results of vocational guidance and educational output showed: ATU $<$ ATE $<$ ATT $>0$, indicating that the promoting effect of the group who accept free policy for secondary vocational education in dimensions of vocational guidance and educational output is higher than those who do not accept the policy (assuming the acceptance).

On the whole, the free policy for secondary vocational education has a certain role in promoting the education quality of secondary vocational schools. Specifically speaking, the free policy for secondary vocational education has a significant positive effect on information resources, vocational guidance and educational output dimensions of secondary vocational schools, but not on the comprehensive factor, course teaching and capacity development, and exposed the problem that targeted objects of the free policy for secondary vocational education is imprecise. Why? firstly from the macro background factors, quantity of secondary vocational school senior teachers from $0.74 \%$ in 2009 dropped to $0.51 \%$ in 2013 , the optimizing degree of student-teacher ratio is small, and the ratio of full-time teachers with high school or less education background is greater than the senior teachers, which exposed the teachers strength of secondary vocational education is weak with no advanced consciousness in line with social practice, therefore, no significant role is played in course teaching and capacity ability; secondly, according to the survey of Qiao Xinyi (2014), it 
shows that growth rate of the dropout of secondary vocational education in each province has different proportion of growth except for in Jiangsu, Zhejiang and Hunan, the highest reaching $1238 \%$, which fully indicates that the implementation of the free policy for secondary vocational education can lessen family economic burden of secondary vocational students in poor areas, but the education quality due to excellent leads to the amazing growth rate of the dropout; thirdly, free assistance funds for secondary vocational schools are shared by the central and local governments and implemented by the provincial fiscal. Provincial and lower-provincial level finance at all levels subsidize students according to public secondary vocational schools tuition standard approved by the provinces (regions and municipalities) and price competent department, and central finance share responsibility for the free policy with local finance in the west area in accordance with an average of 2000 Yuan each year for each student and 8:2 sharing proportion. The implementation of the free policy for secondary vocational school caused the gap of school capital operation which can be covered from finance appropriate subsidies and school enterprise cooperation and post practice, but local financial strength in poor areas is not strong enough to maintain the basic supply, resulting in significant input differences in rich and poor areas, significantly worsening the condition of poor areas, which finally results in the difference of promoting effect of education quality.

Table 5: Free Policy for Secondary Vocational Education Quality Improvement Effect: PSM Estimation

\begin{tabular}{|c|c|c|}
\hline Variable & Sample & $\begin{array}{l}\text { Different Value (Treatment } \\
\text { Group-Control Group) }\end{array}$ \\
\hline \multirow[t]{4}{*}{ Comprehensive factor (F) } & Before matching & 0.313 \\
\hline & ATT & -0.039 \\
\hline & ATU & 0.121 \\
\hline & ATE & -0.034 \\
\hline \multirow[t]{4}{*}{ Course teaching (F1) } & Before matching & 0.862 \\
\hline & ATT & -0.270 \\
\hline & ATU & 0.348 \\
\hline & ATE & -0.252 \\
\hline \multirow[t]{4}{*}{ Information resources $(\mathrm{F} 2)$} & Before matching & 0.077 \\
\hline & ATT & $-1.311^{*}$ \\
\hline & ATU & 0.123 \\
\hline & ATE & -1.270 \\
\hline \multirow[t]{4}{*}{ Vocational guidance (F3) } & Before matching & 0.226 \\
\hline & ATT & $0.675 * *$ \\
\hline & ATU & -0.054 \\
\hline & ATE & 0.654 \\
\hline \multirow[t]{4}{*}{ Educational output (F4) } & Before matching & 0.651 \\
\hline & ATT & $2.614 * * *$ \\
\hline & ATU & 0.725 \\
\hline & ATE & 2.560 \\
\hline \multirow{4}{*}{$\begin{array}{l}\text { Capacity development } \\
\text { (F5) }\end{array}$} & Before matching & 0.241 \\
\hline & ATT & -1.161 \\
\hline & ATU & -0.460 \\
\hline & ATE & -1.141 \\
\hline
\end{tabular}

Note: $* * *, * * *$ respectively indicating significant at level of $10 \%, 5 \%$ and $1 \%$

\section{Conclusion and Policy Implication}

Using the survey data in poor areas of Sichuan Province and drawing on the experience of universal education quality framework of UNESCO that takes learners as the core, this paper 
constructs the evaluation index system of the free policy for secondary vocational education quality, takes "counterfactual inference model" as the theoretical basis to make a quantitative assessment with the improvement effect of free policy on secondary vocational education quality. The research results show that the free policy for secondary vocational education failed to fully improve secondary vocational school education quality, especially far from playing its due role in improving course teaching quality and student ability development of secondary vocational schools, but it has a significant positive effect on information resources, occupational guidance and educational output of secondary vocational education. In addition, the free policy for secondary vocational policy has the problem that targeted objects is imprecise.

The secondary vocational education has the nature of quasi public product and positive external effect and government financial support is a must, but still existing some problems in the implementation process, the free policy for secondary vocational education should have a local adjustment against deficiencies on the basis of maintaining the existing input intensity. Firstly, accelerate the establishment of quality evaluation index system of secondary vocational education to adapt to needs of socio-economic development and labor market, explore the evaluation method involved in the government, students and enterprises participation, and speed up the construction of supervision and management system for the secondary vocational school quality education. Secondly, the free policy for secondary vocational school should adjust the free policy goal on the basis of maintaining the existing input intensity with more attention paid to the quality of secondary vocational education. Based on the continuous implementation of the existing free policy, the fiscal guarantee of secondary vocational education should be focused on improving the quality of secondary vocational education. Establish contact between the financial allocation and secondary vocational school course teaching quality, teaching software and hardware facilities, students ability development and other teaching quality performance to optimize the resources allocation and guide secondary vocational schools consciously improve the quality of running school. Thirdly, screening the free object seriously, identify urban students from poor families and further improve the target object of the free policy for secondary vocational education to improve the efficiency and effectiveness of the financial funds utilizing.

\section{Acknowledgement}

This paper is the partial results of "Implementation Effect Research of Rural Free Policy for Secondary Vocational Education in Poor Areas" (EJA130428) of National Educational Science “Twelve-Five” Plan 2013 Ministry of Education Youth Project, "Study on the Difference of Sichuan Province Rural Tourist Destination Farmers Training Supply and Demand” (No.: CR1321) of Sichuan Province Rural Development Research Center Youth Project, "Study on Poverty and Anti poverty of Migrant Workers in Sichuan” of Sichuan Agricultural University Dual-branch Social Science Project.

\section{References}

[1] Pan Jianhua. Secondary Vocational Education Development in Institutional Change Context-.and Discussion on Assistance Learning and Free Policy for Secondary Vocational Education[J]. Continuing Education Research, 2010,05:78-80.

[2] Chen Yuanyuan. Research on Free Policy for Secondary Vocational Education in China [D]. Southwestern University, 2011.

[3] Chen Shengxiang. The Failure of Free Policy for Secondary Vocational Education in Rural: Manifestations, Causes and Countermeasures [J]., Educational Science, 2011, 27 (5)

[4] Li Minmei. A study on the Fairness Effect of Rural Free Policy for Secondary Vocational Education-Based on the Survey of Jiangxi Province [D]. Master's Degree Thesis of Jiangxi 
Normal University, 2011

[5] Wang Xingxia. Evaluation Research on Free Policy for Secondary Vocational Education [J]. Research on Educational Development, 2012 (17)

[6] Chen Shengxiang, Wang Qiuping. Regional Promotion Strategy Analysis of Rural Free Policy for Secondary Vocational Education -- Based on the Survey of Farmer's Perspective and Regional Comparison[J]. Education Science, 2010,02:78-82.

[7] Wang Wei, Zhong Shaochun, Shang Jianxin. Research on Secondary Vocational Demonstration School Digital Resources System Construction and Promotion Strategy [J]. China Electrified Education, 2014, 05:113-120.

[8] Wang Qin, Ma Shuchao. Strategic Thinking on the Coordinated Development of Secondary and Higher Vocational Education [J]. Chinese Higher Education Research, 2013, 09:99-102+106.

[9] Wang Xingxia. Evaluation Research on Free Policy for Secondary Vocational Education [J]. Research on Educational Development, 2012, 17:25-29

[10] Qiu Xiaojian, Wang Xiande, Tian Lili. Review and Prospect: a Summary of Financial Research on Secondary Vocational Education (2000-2013 year) [J]. Vocational Education Forum, 2014, 10:12-16.

[11] Qiao Xinyi. Regional Difference Analysis on Secondary Vocational Education Needs Change in Free Subsidy Policy - Based on Empirical Analysis of Data from 2006 -2011[J]. Education Science, 2014 04:11-16..

[12] Ran Yunfang. Research on the Coordination and Correlation between Secondary Vocational Education and Urbanization Development [J]-Based on Inter-Provincial Cross-section Data Analysis of 2006 and 2011 [J] Education Development Research, 23:63-69. 2013.

[13] Zhang Xiangming. Historical Mission of Vocational and Technical Schools in the Process of Urbanization [J]. Education Theory and Practice, 2005, 04:20-22.

[14] Research on Secondary Vocational Education Teaching Quality Evaluation System [J]. Vocational Education Forum, 2008, 21:41.

[15] Anu Räisänen,Mari Räkköläinen. Assessment of learning outcomes in Finnish vocational education and training[J]. Assessment in Education: Principles, Policy \& Practice,2014,211.

[16] Alexander Salvisberg,Stefan Sacchi. Labour Market Prospects of Swiss Career Entrants after CompFiona Draper,Crina Oltean-Dumbrava,Chakib Kara-Zaitri,Brian Newbury. Individual learning on environmental vocational education and training courses does not always lead to the workplace application of knowledge and skills[J]. Journal of Education and Work,2014,276.

[17] Li Yu. Shanghai City Secondary Vocational Education External Quality Assurance System Construction under the Background of Vocational Education Great Development [J]. China Vocational and Technical Education, 2011, 14:37-43.

[18] Chen Xiaomin, Hu Lan. Construction of Secondary Vocational School Professional Teaching Quality Assurance System-- Taking Shanghai City Secondary Vocational school as an Example [J]. Vocational Education Forum, 2012, 10:68-72.

[19] Ge Jinlin. Thinking on Secondary Vocational Education School-running Model Changes-from "school-enterprise cooperation" to "school-enterprise integration" [J]. Vocational Education Forum, 2011, 27:34-37. 
[20] Liu Zhihua, Yuan Huting. Shanxi Province Secondary Vocational Education Talents Training model [J]. Education Theory and Practice, 2012, 15:21-23.

[21] Zhu Xiaoping Three Ways of Secondary Vocational Education Course and Content: [J]. Course, Teaching Material, Teaching Method, 2010, 06:14-17.

[22] Yang Zongwu. Strengthening the Construction of Teaching Staff and Promoting the Core Competitive Ability of Vocational Education. Brief Talk on The Current Situation and Countermeasures of the Construction of Teachers' Team in Secondary Vocational Education [J]. China Vocational and Technical Education, 2011, 21:80-82.

[23]Ju Chuanwen. School-running Model Comparison in Five Countries [J]. 2001, 06:24-27.

[24] Li Jian. Cultural Comparison of Secondary Vocational Education Talents Training Model in Five CountSun Ying, Liu Hong, Yang Yingying. Experience and Enlightenment of External Evaluation of Japanese Vocational Education Quality-Taking Higher Vocational School as an Example, [J]. Foreign Education Research, 2014, 05:33-39

[25] Ji Xiaoyan. Reasons Analysis of the Healthy Development of Vocational and Technical Education in SingaWu Xueping, Liu Jinhua. Research on External Quality Evaluation of Secondary Vocational Education in Russia. [J]. Comparative Education Research, 2013, 12:56-60.

[26] Sun Cuixiang, Pang Xueguang. Assessment of Vocational Education: American Experience and Inspiration- Taking American "National Career and Technical Education Evaluation" as an Example, [J]. Foreign Education Research, 2014, 05:13-23.

[27] Ji Xiaoyan. Reasons Analysis of the Healthy Development of Vocational and Technical Education in Singapore [J]. Vocational Education Forum, 2007, 08:62-64

[28] Wu Xueping, Liu Jinhua. Research on External Quality Evaluation of Secondary Vocational Education in Russia. [J]. Comparative Education Research, 2013, 12:56-60

[29] Sun Cuixiang, Pang Xueguang. Assessment of Vocational Education: American Experience and Inspiration- Taking American "National Career and Technical Education Evaluation" as an Example, [J]. Foreign Education Research, 2014, 05:13-23.

[30] Guo Zhigang, Wu Xiwei. Tendency of Value Analysis: Statistical Methods and Applications [M]. Chongqing: Chongqing University Press, 2012.

[31] Liu Zeyun, Qiu Muyuan. Estimation of Quality Gains in Higher Education: a Study Based on Propensity Index Matching [J]. Chinese Population Science, 2011 (5): 85-93. 